retrenchment policy at that time its use was not extended to smaller vessels as proposed. It was, however, supplied and used by foreign countries with quite satisfactory results and at greater depths when using suitable mixtures of oxygen and air. Apparatus on the same principle was used extensiveiy in the last war for midget submarines, human torpedoes, shallow water diving apparatus for removing mines, suits with frog-feet (a very old invention), etc. The midget submarine successfully used against the Tirpitz was built with an emergence chamber, as designed and patented by Sir Robert Davis early in 1915 , the diver using it being equipped with self-contained diving apparatus enabling him to leave the vessel, place an explosive charge; and to return thereto. At the time, however, it was thought that such small vessels couid not be usefully employed.

In the submersible decompression chamber invented by Sir Robert oxygen is breathed by the diver during decompression from $60 \mathrm{ft}$. $(18.3 \mathrm{~m}$.) to the surface to shorten the decompression time. No oxygen poisoning symptoms have resulted during the many times of its use. Dr. Donald's results show that shallower depths are not always safe. The mixture of oxygen and air should, therefore, always be used as recommended by Sir Robert Davis.

The greater risk of oxygen poisoning found by Dr. Donald in under-water experiments cannot, he says, be attributed to $\mathrm{CO}_{2}$ accumulation, which, as shown by me, enhances oxygen poisoning. He found no excess of $\mathrm{CO}_{3}$ in the breathing chamber, but has left out of account the dead space of the mouthpiece and respiratory air-tubes. An experienced diver told me he believed the effect was due to rapid shallow breathing by less experienced and stable men when under water. Such breathing would greatly enhance the effect of the $\mathrm{CO}_{2}$ in the dead space.

Argyll Campbell showed that oxygen breathing interferes with the transport of $\mathrm{CO}_{2}$ from the tissues and puts up its tissue partial pressure greatly. Similarly Bean, J. W. (Physiol. Rev., 1945, 25, 1), has pointed out that nitrogen, and still more the heavier gas argon, at high pressures interferes with the diffusion outwards of $\mathrm{CO}_{2}$ from the lungs. Helium and hydrogen, owing to their light weight, have in comparison no such effect, and have no narcotic effect when used with oxygen for deep diving. $\mathrm{CO}_{2}$ may then be the cause both of oxygen poisoning symptoms and the anaesthetic effect of nitrogen in deep dives. This last question can be settled by measuring the partial pressure of $\mathrm{CO}_{2}$ in the tissues when breathing argon and oxygen. The heavier gases krypton and xenon have much greater effect, but are very difficult to obtain (Lawrence, J. H., et al., J. Physiol, 1946, 105, 197). So soon as enough argon can be obtained a trial will be made.

I may add that a copy of Dr. Donald's report to the Admiralty was shown to me a year or two ago, and I then pointed out the claims of Sir Robert Davis for adequate recognition, but no notice of these has been taken.-I am, etc.,

Chalfont St. Peter, Bucks. LEONARD HiLl.

\section{Refrigeration Anaesthesia}

SIR,- - In his interesting article on the results of refrigeration analgesia in Melbourne Mr. E. S. R. Hughes (May 31, p. 761) seems to have reached much the same conclusions as British anaesthetists. At the same time there is one point which should, I think, be clarified. Mr. Hughes does not regard a tourniquet or its equivalent as of much importance-for example, "the tourniquet is not an essential requirement at any stage of the procedure and may be dispensed with altogether." With all deference may I suggest that the proper application of a tourniquet is an essential and indeed a vital part of the technique?

If a limb of an aged and toxic patient is cooled down to $5^{\circ} \mathrm{C}$ without a tourniquet, the process takes a long time and is accompanied by a pronounced fall in the general body temperature. This is a most dangerous condition and is frequently followed by gradual deterioration and eventual heart failure, often associated with anuria and a low-grade bronchopneumonia. It will be noticed that in Mr. Hughes's series of 25 amputations under refrigeration the total mortality rate was $44 \%$, while $20 \%$ of cases developed a fatal bronchopneumonia. These figures seem high, and it would be interesting to know how many of the fatal cases were refrigerated without a tourniquet. The latter device can be applied painlessly if a sausage-shaped ice bag is applied at the appropriate level round the limb for 30 minutes beforehand. The time for subsequent refrigeration can then be reduced to $1 \frac{3}{4}$ to 2 hours. In our experience it is better to avoid post-operative refrigeration of the stump in spite of some theoretical advantages.

It may be argued by those who dislike tourniquets that therapeutic limb cooling is often carried out without them in cases of defective circulation in order to lower the tissue metabolic rate to a point at which the limited blood flow is adequate. This is true, but the necessary temperature drop is not great, and such patients are usually younger and fitter than those undergoing amputation for gangrene.- I am, etc.,

St. Albans.

C. LANGTon Hewer.

\section{Basal-cell Carcinoma at Site of Trauma}

SIR,-Trauma rarely figures in the aetiology of basal-cell carcinoma. The following case is similar to that recently recorded by Reah (1947).

\section{CASE Report}

Male, aged 38, brunet, normal skin texture. In 1943, recantured after some months at liberty in Germany after escape from prison camp, he was beaten about the head and face with a revolver butt. Lacerations were produced on the forehead, cheek, and nose, and were sutured shortly afterwards, stitches being removed after about a week. All the wounds healed normally except for one gash on the forehead over the outer end of the left eyebrow.

This lesion never healed completely, and it discharged a little pus until early in 1947, when it dried up. There had been a very slow peripheral spread during the whole time. When first seen in March, 1947, the lesion was a typical superficial cicatrizing basal-cell carcinoma, $3 / 4$ in. by $1 / 2$ in. $(1.9 \mathrm{~cm}$. by $1.25 \mathrm{~cm}$.), with central scarring and elevated pearly edge. The diagnosis was confirmed by biopsy.

-I am, etc.,

London. S.W.1.

James Marshall.

Reah, T. G. (1947). British Medical Journal, 1, 412.

\section{Pethidine in Labour}

SIR,-I would like to comment on that masterly paper by Miss Josephine Barnes (April 5, p. 437) on the use of pethidine in labour. I must say that I have not been so favourably impressed by the results following the use of this drug. I agree with your correspondent, Dr. James Ross (May 24, p. 738), when he says that "its action is unreliable." That has been my own experience.

I cannot agree with Miss Barnes that pethidine satisfies the first part of her No. 1 criterion. In my experience-a much smaller one than that of Miss Barnes-an alarming, sudden, and anxious drop in blood pressure has immediately followed the administration of the drug in several cases. As regards the effect of pethidine on the baby, I have almost always found the infant slow to breathe and giving definite cause for worry, even in cases where such could not be attributed to operative interference or abnormality of any kind. Like Dr. Ross I believe heroin (diamorphine hydrochloride) to be a vastly safer and more reliable drug, and I have discarded pethidine altogether.- I am, etc.,

$$
\text { Belfast. }
$$

$$
\text { J. H. P. GIFF. }
$$

\section{Behcet's Syndrome}

SIR,-Dr. E. W. Prosser Thomas's article on Behcet's syndrome (Jan. 4, p. 14) has just come to my notice, and I think it will be of interest to express our views on the so-called syndrome as well as on thrombophlebitis. In the Proceedings of the Medical Society of Athens (1930, p. 586) Dr. B. Adamantiades presented the first known case of recurrent iritis with hypopyon, insisting at the same time on the small ulcerations of the mouth and genitalia. All these three elements were characterized by recurrences, appearing either at the same time or at independent periods. Later (Annales d'Oculistique, $1931,168,271)$ followed the same description of this syndrome in French. In 1931 Dr. Daskalopoulos (Proceedings of the Greek Medical Society, Athens, p. 717) describes a record case. There follows the description of Whitwell (1934); and later again in 1937 Behcet, of Constantinople, describes the syndrome in the Dermatologische Wochenschrift $(\mathbf{1 0 5}, 1152)$, in German.

The same author (Dr. Adamantiades), in a careful study of two other cases which came under his notice, found that a fourth element is quite common and describes in detail the thrombophlebitis either of the central vein of the retina or of the legs (Greek Ophthalmic Society, June 7, 1945, and Annales d'Oculistique, 1946, 179, 143). This element was also observed by Urbanek, J. (Zt. f. Augenh., 1929, 69, 174), 